\title{
Bone Loss and Radiographic Damage Profile in Rheumatoid Arthritis Moroccan Patients
}

\author{
Hamida Azzouzi, Linda Ichchou \\ Department of Rheumatology, Mohammed VI University Hospital, Faculty of Medicine, Mohammed I University, Oujda, Morocco
}

\author{
Corresponding author \\ Hamida Azzouzi \\ Department of Rheumatology, Mohammed VI \\ University Hospital, Faculty of Medicine, \\ Mohammed I University, BP 4806 Oujda \\ Université 60049 Oujda, Morocco \\ Tel: +212-660539894 \\ Fax: +212-536531919 \\ E-mail: hamida.azzouzi@gmail.com
}

Received: February 26, 2021

Revised: April 27, 2021

Accepted: May 2, 2021
Background: Rheumatoid arthritis (RA) is a known cause of joint destruction and systemic bone loss. In this study, we aimed to evaluate the bone damage and bone loss profiles of established RA patients. Methods: We designed a cross-sectional study on a cohort of established RA patients. The bone evaluation was performed by obtaining standard X-ray images of hands and feet combined with bone mineral density (BMD) measurements. Radiographic joint damage was calculated by the modified total Sharp / van der Heijde score (mTSS). BMD was obtained by performing dual energy X-ray absorptiometry of the lumbar spine and femoral neck. Data on age, smoking, alcoholism, steroid prescription, body mass index (BMI), disease duration, disease activity, and functional disability were collected. Results: $A$ total of 93 RA patients were recruited. Their mean age was $51.59 \pm 12.38$ years, with a mean disease duration of $12.07 \pm 9.19$ years. $A$ total of $36.6 \%$ of patients had osteoporosis, and the mean mTSS was $70.33 \pm 48.93$. Both hip $(P=0.0005)$ and lumbar BMD $(P=0.0005)$ were correlated with mTSS. Backward regression analyses determined that bone damage was associated with high titers of rheumatoid factor, low lumbar BMD, and low BMI. General bone loss was associated with gender, steroid dose, steroid duration, menopause, and BMI. Conclusions: Bone damage was associated with low BMI and axial bone loss in our RA population.

Key Words: Arthritis, rheumatoid · Bone density · Disability evaluation

\section{INTRODUCTION}

Rheumatoid arthritis (RA) is a frequent connective tissue disease, which results in disability and bone damage. Inflammation in the synovial membrane of joints explains bone damage in situ. The general bone loss in RA is very intricate. Several combined factors (e.g., inflammation, glucocorticoid (GC) chronic use, menopause, and disease-related weight loss) are the main factors leading to bone loss in RA.[1,2]

Inflammation and bone loss in RA are closely linked processes. The systemic in-

Copyright $@ 2021$ The Korean Society for Bone and Mineral Research

This is an Open Access article distributed under the terms of the Creative Commons Attribution Non-Commercial License (https://creativecommons.org/licenses/by-nc/4.0/) which permits unrestricted non-commercial use, distribution, and reproduction in any medium, provided the original work is properly cited. flammatory condition observed in RA leads to generalized reduced bone quality by encouraging osteoclast activity and inhibiting the reparative activity of osteoblasts.[3] Although focal and generalized bone loss is a combined phenomenon in RA, which is partially explained by the underlying inflammatory process, their correlation is subject to various modifying factors, such as treatments, $[4,5]$ and tends to vary according to the disease course.[6] Furthermore, sex and ethnic differences regarding bone constitution and formation are well documented.[7,8] 
Men and those with African origins exhibit larger bone surfaces and higher trabecular bone density than females or other races (Caucasian), respectively.[7] This may result in different RA profiles regarding bone loss. Studies on bone loss and damage profiles in established RA are scarce, especially in our context. We hypothesized that bone damage is associated with bone loss in our RA patients. Therefore, our objective was to evaluate bone destruction and osteoporosis profile in our established RA patients, determine their relationship, and investigate the associated factors with radiographic joint damage and bone loss.

\section{METHODS}

\section{Study design}

We performed a cross-sectional study on established RA patients seeking care at our Rheumatology Department. We have included in the study the patients that were seen from October to December 2015.

\section{Subjects}

RA diagnosis was made according to the American College of Rheumatology (ACR) and European League Against Rheumatism (EULAR) 2010 criteria. The patients with prior specific bone treatment, liver cirrhosis, renal insufficiency, primary hyperparathyroidism, and cancer were excluded. The study was conducted in accordance with the declaration of Helsinki, and all patients provided informed written consent prior to the study.

\section{Bone evaluation}

The bone mineral density (BMD) was measured with a dual energy X-ray absorptiometry (DXA) Lunar Prodigy DXA system version 12.3 (GE Healthcare, Madison, WI, USA) in 2 sites (femur and lumbar spine). Femur neck (FN) BMD was determined on the basis of a dual femur technique in $\mathrm{g} /$ $\mathrm{cm}^{2}$; lumbar BMD was evaluated from an anteroposterior view of $L 1-4$. Hip BMD refers to the mean value of both FN BMDs. Osteoporosis was defined according to the World Health Organization classification ( $t$-score $<-2.5$ in the spine and/or hip). The structural evaluation was performed simultaneously with BMD determination. The bone damage (erosion and joint narrowing) in hands and feet was calculated based on X-ray images according to the modified Sharp van der Heijde score (mTSS).[9] Two rheumatologists (M.L and L.L after a period of training) separately performed the calculation; in the case of non-concordance, a third rheumatologist performed the calculation, and an average estimation was obtained.

\section{Data collection}

The demographic data on age, gender, smoking, alcoholism status, and menopause were collected. In addition, the patients were asked whether they performed regular physical activity (more than 30 min of jogging per day or equivalent). Information on the disease duration, GC prescription (actual dosage, duration, withdrawal), and disease-modifying anti-rheumatic drug treatments were assessed. The body mass index (BMI) was calculated from each patient's height and weight (weight/height ${ }^{2}$ ); the latter 2 measurements used the same scale as that for BMD calculation. We used a composite index, the disease activity score for 28 joints for RA with erythrocyte sedimentation rate (DAS28-ESR).[10] The components of DAS28 were obtained within the current evaluation. The ESR was measured for each patient. Remission was defined by DAS28 <2.6. Whereas low disease activity was considered when DAS28 was between 2.6 and 3.2, mild disease activity ranged from 3.2 to 5.1 , and high disease activity was attributed to DAS28 $>$ 5.1. We had concomitantly assessed functional disability using the health assessment questionnaire (HAQ).[11] The latter's final score ranged from 0 (no handicap) to 3 (highly impaired). Information on the rheumatoid factor (RF) titer and anti-Cyclic Citrullinated Peptide Antibodies was extracted from the patients' medical records.

\section{Statistical analysis}

The data were analyzed by the Statistical Package for the Social Sciences 20 software (SPSS Inc., Chicago, IL, USA). First, a descriptive study was made for each variable. Then, bivariate correlation (Pearson or Spearman test) was performed between 2 continuous variables to identify any significant association with bone damage (mTSS) or bone loss. We used analysis of variance (ANOVA) for quantitative variable analysis. Shapiro-Wilk test was used to evaluate normality. Multiple backward linear (mTSS, BMD) and logistic (osteoporosis) regressions were performed to identify factors associated with radiographic damage and osteoporosis in our patients. We used the variance inflation factor (VIF) test to study multicollinearity. The VIF test demon- 
strated null multicollinearity (VIF=1) for the independent variables studied. There was modest multicollinearity detected for menopause duration and age $(\mathrm{VIF}=5)$ that did not affect other independent factors at the used models. A $P$ value under 0.05 was considered to be statistically significant.

\section{RESULTS}

\section{RA population characteristics}

The study included 93 RA patients. They were middle-aged patients (51.59 \pm 12.38 years old) with a mean disease duration of $12.07 \pm 9.19$ years. The diagnosis of RA was made

Table 1. Demographic and disease characteristics of our population

\begin{tabular}{lc}
\hline Characteristic & $\begin{array}{c}\text { Mean } \pm \text { SD or N (\%) } \\
\text { (N=93) }\end{array}$ \\
\hline Age (yr) & $51.59 \pm 12.38$ \\
Women & $82(88.2)$ \\
BMI (kg/m²) & $25.42 \pm 5.01$ \\
Positive RF & $77(82.8)$ \\
Positive ACPA & $74(79.6)$ \\
ESR (mm/h) & $31.4 \pm 27.1$ \\
Disease duration (yr) & $12.07 \pm 9.19$ \\
Current steroid use & $71(76.3)$ \\
Steroid use duration, median (min-max) & $36(0-360)$ \\
(month) & \\
DMARDs & \\
MTX monotherapy & $88(94.6)$ \\
Combined MTX with sulfasalazine or HCO & $11(11.8)$ \\
HCO & $23(24.7)$ \\
Biologic DMARDs & $8(8.6)$ \\
Comorbidities & \\
Diabetes & $6(6.5)$ \\
Hypertension & $9(9.7)$ \\
Thyroid disease & $5(5.4)$ \\
DAS28 & $3.93 \pm 1.81$ \\
HA0 (range 0-3) & $1.08 \pm 0.99$ \\
mTSS (hands and feet, range 0-448) & $70.33 \pm 48.93$ \\
Osteoporosis & $34(36.6)$ \\
Hip BMD (g/cm²) & $0.884 \pm 0.163$ \\
Lumbar spine T-score & $-1.72 \pm 1.43$ \\
Hip T-score & $-1.15 \pm 1.33$ \\
\hline BH & \\
\hline
\end{tabular}

$\mathrm{BMI}$, body mass index; RF, rheumatoid factor; ACPA, anti-Cyclic Citrullinated Peptide Antibody; ESR, erythrocyte sedimentation rate; DMARDs, disease modifying anti-rheumatic drugs; MTX, methotrexate; $\mathrm{HCQ}$, hydroxychloroquine; DAS28, disease activity score 28; HAO, health assessment questionnaire; mTSS, modified total Sharp-van der Heijde score; BMD, bone mineral density; SD, stadard deviation.
24 (12-72) months, as a median, after the onset of symptoms. The patients were slightly disabled (the mean of HAQ was $1.08 \pm 0.99)$. Patients were in a remission state in $30.1 \%$ (28) and low disease activity in $16.1 \%$ (15). Mild and high disease activity was found in $22(23.7 \%)$ and $28(30.1 \%)$ patients, respectively. Comorbidities were present in 18 (19.3\%) patients. They were a majority to receive methotrexate (94.6\%). Osteoporosis was present in $36.6 \%$ of our patients, and their average mTSS score was $70.33 \pm 48.93$ (Table 1).

\section{Osteoporosis classical factors}

A total of $86.8 \%$ of our patients used or were using GC at the moment of the study; 13 patients smoked, and 3 were alcoholics. Menopause was recorded among 43 patients with a mean duration of $8.15 \pm 7.71$ years. We have assessed 6 cases of body thinness (BMI under 19). Only 12\% of our patients declared to perform regular physical activity. There was no significant difference when comparing RA osteoporotic and non-osteoporotic patients regarding smoking, alcoholism, physical activity, and body thinness. However, women with osteoporosis were predominantly menopausal $(61.8 \%)$, while $37.3 \%$ had menopause in the non-osteoporotic group.

\section{Predictors of radiographic damage}

Age, functional disability (HAQ), disease duration, GC use duration, and menopause duration were positively corre-

Table 2. Associated factors with mTSS, hip and spine BMD using correlations

\begin{tabular}{|c|c|c|c|}
\hline & & $P$-value & \\
\hline & mTSS & Hip BMD & Lumbar BMD \\
\hline Age & $0.293^{\text {a) }}$ & $-0.306^{\mathrm{al}}$ & $-0.406^{b)}$ \\
\hline Disease duration & $0.475^{\mathrm{bl}}$ & $-0.233^{\mathrm{a})}$ & $-0.178^{c)}$ \\
\hline BMI & $-0.257^{\mathrm{a})}$ & $0.474^{\text {b) }}$ & $0.306^{\mathrm{a})}$ \\
\hline $\mathrm{HAO}$ & $0.307^{\text {a) }}$ & $-0.209^{c)}$ & $-0.247^{\mathrm{a})}$ \\
\hline DAS28 & $0.128^{\mathrm{c})}$ & $-0.180^{c)}$ & $-0.210^{c)}$ \\
\hline GC use duration & $0.290^{\text {a) }}$ & $-0.289^{a)}$ & $-0.329^{\text {a) }}$ \\
\hline GC dose & $0.200^{c)}$ & $-0.155^{c)}$ & $-0.214^{c)}$ \\
\hline Menopause duration & $0.259^{\text {a) }}$ & $-0.326^{a)}$ & $-0.364^{a)}$ \\
\hline Hip BMD & $-0.479^{b)}$ & - & - \\
\hline Spine BMD & $-0.379^{b)}$ & - & - \\
\hline
\end{tabular}

${ }^{\text {a) }}<0.05 .{ }^{\text {b) }}<0.001 .{ }^{\text {c) }}>0.05$.

$\mathrm{BMI}$, body mass index; $\mathrm{HAO}$, health assessment questionnaire; DAS28, disease activity score 28; GC, glucocorticoid; BMD, bone mineral density; mTSS, modified total Sharp-van der Heijde score. 

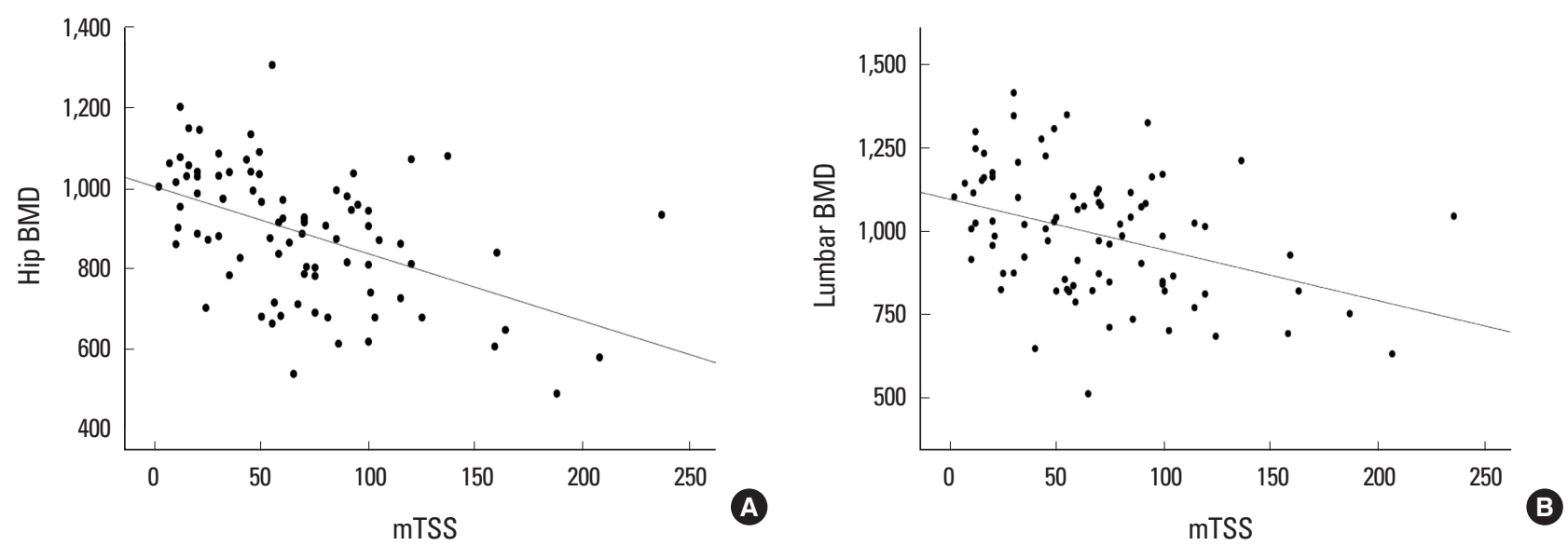

Fig. 1. Scatter plots of the modified total Sharp-van der Heijde score (mTSS) with (A) hip bone mineral density (BMD) and (B) lumbar BMD in our population.

lated with mTSS. On the other side, BMI and BMD (hip and spine) were negatively correlated with mTSS (Table 2 and Fig. 1). These variables were associated with bone damage, as determined by univariate linear regression (Table 3 ).

However, only high titer of RF with low lumbar BMD and low BMI were associated with mTSS in the multivariate backward regression model, including all associated factors (Table 3). Smoking was included in that model but did not reach significance.

\section{Factors associated with bone loss}

RA osteoporotic patients had significantly $(P=0.001)$ higher mean mTSS (91.97 \pm 46.85$)$ than those without osteoporosis $(57.86 \pm 46.02)$. In logistic multivariate backward regression, osteoporosis was associated with gender $(P=0.01)$, GC use duration ( $P=0.028), \mathrm{GC}$ dose $(P=0.01)$, menopause $(P=0.003)$, and BMI ( $P=0.001$; Table 4$)$.

Age, disease, menopause, and steroid use duration, were negatively correlated to hip and lumbar BMD. Only BMI demonstrated a positive correlation with BMD (hip and lumbar) in our study (Table 2). At regressions, menopause was negatively associated with lumbar BMD $(P=0.02)$, while disease duration was unassociated (Table 3). Multivariate backward linear regression revealed that lumbar BMD was best explained by age, GC dose, and BMI (Table 3).

\section{DISCUSSION}

In this study, Bone damage was best explained by positive RF, smoking, lumbar BMD, and BMI. Nevertheless, it was positively associated with age, functional disability, GC use duration, and disease duration. On top of that, bone loss was associated with age, menopause, GC dose, and GC duration. $\mathrm{BMI}$ was a protective factor of both bone loss and bone damage in our study. These findings were in perfect agreement with the results reported in the literature. Lateonset $[12,13]$ and longstanding RA disease [14] are known to be aggressive. On top of that, GC use duration was positively associated with mTSS. This could be explained by the heterogeneity of this population regarding disease duration and recent introduction of synthetic DMARDs. In our area, the diagnosis delay of RA was long (i.e., 24 [12-72] months), and many recruited patients were only on GC auto medication and never received a prior DMARD treatment (data not shown). The association between disability and joint destruction is controversial in the literature. We determined a positive significant association between $\mathrm{HAQ}$ and mTSS, which was also shown by Sivas et al. [14]; a positive significant association was also observed between disability scores and other measurement methods of radiographic damage. In addition, HAQ was also individualized as an independent predictor of radiographic progression in a Korean cohort.[15] It is possible that other studies $[16,17]$ did not observe this association owing to the duration of studies and baseline HAQs. Severe disease is associated with a high HAQ score at the baseline,[18] which can explain the predictive ability of $\mathrm{HAQ}$ for joint damage.

Interestingly, BMI was inversely correlated with the Sharp scores. In our study, obesity appeared to be a protective factor for joint destruction in established RA. Several stud- 


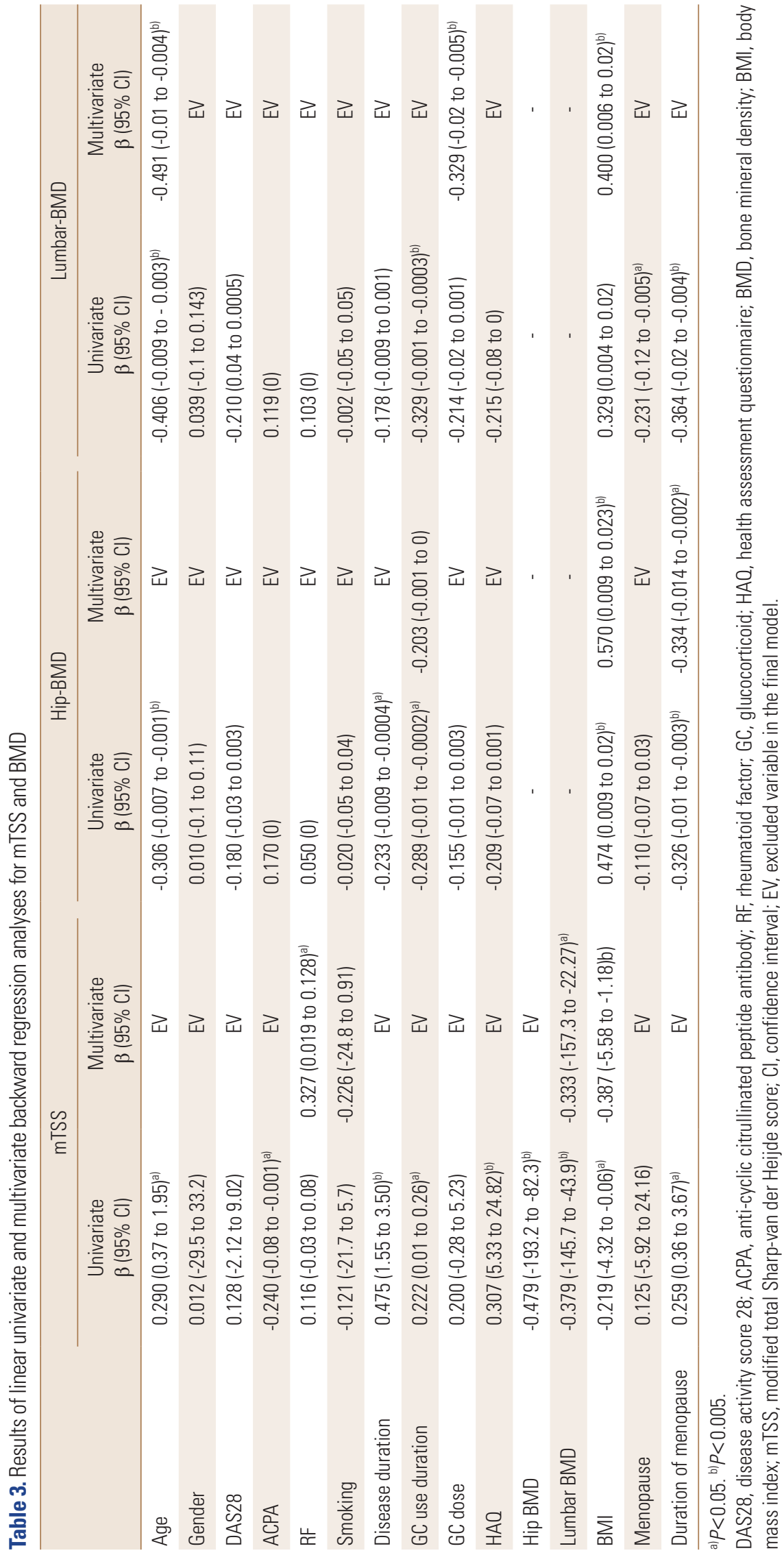


Table 4. Univariate and multivariate backward logistic regressions for osteoporosis

\begin{tabular}{|c|c|c|}
\hline & \multicolumn{2}{|c|}{ Osteoporosis } \\
\hline & $\begin{array}{l}\text { Univariate } \\
\text { OR (95\% Cl) }\end{array}$ & $\begin{array}{l}\text { Multivariate } \\
\text { OR (95\% Cl) }\end{array}$ \\
\hline Age & $1.06(1.02 \text { to } 1.1)^{b)}$ & EV \\
\hline mTSS & $1.016(1.005 \text { to } 1.026)^{b)}$ & EV \\
\hline Gender (female) & 1.01 (0.27 to 3.73$)$ & $71.52(2.48 \text { to } 2055.6)^{\text {a) }}$ \\
\hline BMI & $0.88(0.79 \text { to } 0.97)^{\mathrm{a})}$ & $0.71(0.58 \text { to } 0.86)^{b)}$ \\
\hline Menopause & 1.72 (0.9 to 3.27 ) & $12.46(2.34 \text { to } 66.26)^{b)}$ \\
\hline Duration of menopause & $1.1(1.01 \text { to } 1.18)^{a)}$ & EV \\
\hline ACPA positivity & 0.94 (0.3 to 2.8) & EV \\
\hline RF positivity & 0.70 (0.22 to 2.27$)$ & EV \\
\hline DAS28 & 1.21 (0.95 to 1.54$)$ & EV \\
\hline Smoking & 1.06 (0.6 to 1.87 ) & EV \\
\hline Disease duration & 1.01 (0.96 to 1.06$)$ & EV \\
\hline GC use duration & $1.007(1.001 \text { to } 1.01)^{\mathrm{a})}$ & $1.009(1.001 \text { to } 1.02)^{a)}$ \\
\hline GC dose & 1.13 (0.99 to 1.27$)$ & $1.24(1.04 \text { to } 1.48)^{a)}$ \\
\hline HAO & 1.39 (0.9 to 2.14$)$ & EV \\
\hline
\end{tabular}

a) $P<0.05$. ${ }^{\text {b) }} P<0.005$.

mTSS, modified total Sharp-van der Heijde score; BMI, body mass index; ACPA, anti-cyclic citrullinated peptide antibody; RF, rheumatoid factor; DAS28, disease activity score 28; GC, glucocorticoid; $\mathrm{HAO}$, health assessment questionnaire; $\mathrm{OR}$, odds ratio; $\mathrm{Cl}$, confidence interval; $\mathrm{EV}$, excluded variable in the final model.

ies have shown this association between $\mathrm{BMI}$ and bone damage.[19-21] It has been also reported that low BMI is a significant predictor of radiographic progression in Caucasian and Korean populations with early RA.[15,22] To explain this paradoxical fact, some theories have been proposed such as the mechanical effect of greater weight and greater muscle mass on bone remodeling,[22] or the effect of aggressive therapy conducted in obese patients based on their habitual high DAS activity.[21] Studies focusing on adipocytokines in RA indicated that the levels of adiponectin $[23,24]$ or leptin $[25]$ could be associated with radiological damage. The molecular mechanism of this association is yet unknown.

A high titer of the RF was associated with mTSS in this study. Studies suggested that RF and anti-cyclic citrullinated proteins antibodies had a potentially significant role in erosion even in the absence of inflammation.[26] RF even determines radiographic progression independently of disease activity in a study of 5 RA clinical trials.[27] These clinical observations are supported by the increased Fc-receptor expression during osteoclastogenesis and the effective stimulation of osteoclasts differentiation by immune complexes in vivo and in vitro studies.[26]

We have demonstrated a good correlation between hip, lumbar BMD, and joint damage, but only lumbar BMD remained negatively associated with mTSS at the multivariate model. This association has been previously reported in studies focusing on established RA.[28,29] While in early $R A$, this finding seems to be more evident, especially in hands.[30,31] In established RA, this association is diluted by emergent confounding factors, especially for hip BMD. [28] Moreover, Zhang et al. [29] showed that generalized bone loss was an independent predictor of joint radiographic progression.

Several studies have shown lower BMD in RA than that in controls; the largest effect has been measured in the hip.[2,32] In the current study, the lumbar-spine $t$-score was lower than the total hip $t$-score and was affected by menopause. Hip BMD was associated with disease duration and not menopause status. This can be explained by the osteoporosis profile seen in RA, which is more pronounced in cortical bone.[1,33] In our RA patients, we observed factors associated with bone loss that were similar to those cited in the literature. Steroid dose and use duration were associated with bone loss. Some studies have shown that GC use was not an overall predictor of BMD loss, rather its use duration was a predictor.[34] The impact of steroids on bone health is also complex. GCs are known to induce osteoporosis in healthy bone,[35] it is a doseand duration-dependent effect. In RA, steroids reverse inflammation, which is the direct cause of bone loss and damage by the disease. A recent longitudinal study (10 years of follow-up) has shown that the use of steroids was not associated with bone loss; however, the cumulative steroid dose was significantly associated with the total hip BMD in the first 2 years of RA evolution.[36] The effect of steroids on RA bone is not only a dose- and duration-dependent effect but also probably a site-effect. Engvall has determined that low-dose Prednisolone in early RA counteracts the negative effects of rheumatoid inflammation in bone tissue in the hip but not in the lumbar spine, especially in postmenopausal women.[5] These data show the multifaceted condition of bone loss in RA.

In this study, BMI was highly correlated with BMD and had a protective effect on bone loss in our RA patients. The association between obesity and RA appeared to be controversial. Although both diseases are inflammatory and 
result in high morbidity and mortality, obesity is associated with less bone erosion and osteoporosis in patients with RA.[37] The effect of high BMI on bone can be partially explained by the estrogenic role in bone remodeling and the mechanical bone loading effect.

Finally, our study's objective was to develop a profile of factors associated with bone loss and joint damage in established RA. Some limits should be mentioned. Specifically, the cross-sectional design would not permit prediction models. Besides, we used backward regression analysis to make easily interpretable models; however, stepwise analyses were criticized for possible false inclusion or exclusion of correlated independent variables.[38] Also, hand BMD could not be measured at the time of the study.

\section{CONCLUSION}

In this study, joint damage was associated with BMD loss in our established RA patients. The generalized bone loss was also predicted by steroid dose, steroid duration, menopause, and gender; high BMI was a protective factor for bone loss and local damage in our RA population.

\section{DECLARATIONS}

\section{Acknowledgments}

The authors acknowledge the contribution made by Drs. O. Akkar, M. Lehraiki, L. Lehlou, and L. Boutouala in data acquisition. The paper was presented at the 2016 ARLAR meeting and accepted as an abstract at the 2016 EULAR annual congress.

\section{Funding}

The authors received no financial support for this article.

\section{Ethics approval and consent to participate}

This study conformed to the ethical guidelines of the 1975 Declaration of Helsinki and was approved.

\section{Conflict of interest}

No potential conflict of interest relevant to this article was reported.

\section{ORCID}

Hamida Azzouzi

https://orcid.org/0000-0001-8978-1605
Linda Ichchou https://orcid.org/0000-0002-2733-5594

\section{REFERENCES}

1. Fassio A, Idolazzi L, Jaber MA, et al. The negative bone effects of the disease and of chronic corticosteroid treatment in premenopausal women affected by rheumatoid arthritis. Reumatismo 2016;68:65-71. https://doi.org/10.4081/ reumatismo.2016.878.

2. Shibuya $\mathrm{K}$, Hagino H, Morio $\mathrm{Y}$, et al. Cross-sectional and longitudinal study of osteoporosis in patients with rheumatoid arthritis. Clin Rheumatol 2002;21:150-8. https:// doi.org/10.1007/s10067-002-8274-7.

3. Wehmeyer C, Pap T, Buckley CD, et al. The role of stromal cells in inflammatory bone loss. Clin Exp Immunol 2017; 189:1-11. https://doi.org/10.1111/cei.12979.

4. Ørnbjerg LM. Structural joint damage and hand bone loss in patients with rheumatoid arthritis. Dan Med J 2018;65: B5452.

5. Engvall IL, Svensson B, Tengstrand B, et al. Impact of lowdose prednisolone on bone synthesis and resorption in early rheumatoid arthritis: experiences from a two-year randomized study. Arthritis Res Ther 2008;10:R128. https:// doi.org/10.1186/ar2542.

6. Hoff M, Haugeberg G, Kvien TK. Hand bone loss as an outcome measure in established rheumatoid arthritis: 2-year observational study comparing cortical and total bone loss. Arthritis Res Ther 2007;9:R81. https://doi.org/10.1186/ ar2280.

7. Saeed I, Carpenter RD, Leblanc AD, et al. Quantitative computed tomography reveals the effects of race and sex on bone size and trabecular and cortical bone density. J Clin Densitom 2009;12:330-6. https://doi.org/10.1016/j.jocd. 2009.04.001.

8. Leder BZ, Araujo AB, Travison TG, et al. Racial and ethnic differences in bone turnover markers in men. J Clin Endocrinol Metab 2007;92:3453-7. https://doi.org/10.1210/jc. 2006-2695.

9. van der Heijde D. How to read radiographs according to the Sharp/van der Heijde method. J Rheumatol 2000;27: 261-3.

10. Prevoo ML, van 't Hof MA, Kuper HH, et al. Modified disease activity scores that include twenty-eight-joint counts. Development and validation in a prospective longitudinal study of patients with rheumatoid arthritis. Arthritis Rheum 
1995;38:44-8. https://doi.org/10.1002/art.1780380107.

11. Guillemin F, Brainçon S, Pourel J. Measurement of the functional capacity in rheumatoid polyarthritis: a French adaptation of the Health Assessment Questionnaire (HAQ). Rev Rhum Mal Osteoartic 1991;58:459-65.

12. van Schaardenburg D, Breedveld FC. Elderly-onset rheumatoid arthritis. Semin Arthritis Rheum 1994;23:367-78. https://doi.org/10.1016/0049-0172(94)90087-6.

13. Innala $L$, Berglin $E$, Möller B, et al. Age at onset determines severity and choice of treatment in early rheumatoid arthritis: a prospective study. Arthritis Res Ther 2014;16:R94. https://doi.org/10.1186/ar4540.

14. Sivas F, Barça N, Onder M, et al. The relation between joint erosion and generalized osteoporosis and disease activity in patients with rheumatoid arthritis. Rheumatol Int 2006; 26:896-9. https://doi.org/10.1007/s00296-006-0104-9.

15. Joo YB, Bang SY, Ryu JA, et al. Predictors of severe radiographic progression in patients with early rheumatoid arthritis: A Prospective observational cohort study. Int J Rheum Dis 2017;20:1437-46. https://doi.org/10.1111/1756-185x. 13054.

16. Saevarsdottir S, Rezaei H, Geborek P, et al. Current smoking status is a strong predictor of radiographic progression in early rheumatoid arthritis: results from the SWEFOT trial. Ann Rheum Dis 2015;74:1509-14. https://doi.org/ 10.1136/annrheumdis-2013-204601.

17. Mouterde G, Lukas C, Logeart I, et al. Predictors of radiographic progression in the ESPOIR cohort: the season of first symptoms may influence the short-term outcome in early arthritis. Ann Rheum Dis 2011;70:1251-6. https://doi. org/10.1136/ard.2010.144402.

18. Nair SC, Bijlsma JW, van der Werf JH, et al. Do radiographic joint damage and disease activity influence functional disability through different mechanisms? Direct and indirect effects of disease activity in established rheumatoid arthritis. J Rheumatol 2013;40:1505-12. https://doi.org/10.3899/ jrheum. 121346.

19. Tekaya R, Sahli H, Zribi S, et al. L'obésité est un facteur protecteur contre l'atteinte structurale au cours de la polyarthrite rhumatoïde. Tunis Med 2011;89:462-5.

20. van der Helm-van Mil AH, van der Kooij SM, Allaart CF, et al. A high body mass index has a protective effect on the amount of joint destruction in small joints in early rheumatoid arthritis. Ann Rheum Dis 2008;67:769-74. https:// doi.org/10.1136/ard.2007.078832.
21. Vidal C, Barnetche T, Morel J, et al. Association of body mass index categories with disease activity and radiographic joint damage in rheumatoid arthritis: A systematic review and metaanalysis. J Rheumatol 2015;42:2261-9. https:// doi.org/10.3899/jrheum.150224.

22. Baker JF, Ostergaard M, George M, et al. Greater body mass independently predicts less radiographic progression on X-ray and MRI over 1-2 years. Ann Rheum Dis 2014;73:19238. https://doi.org/10.1136/annrheumdis-2014-205544.

23. Meyer M, Sellam J, Fellahi S, et al. Serum level of adiponectin is a surrogate independent biomarker of radiographic disease progression in early rheumatoid arthritis: results from the ESPOIR cohort. Arthritis Res Ther 2013;15:R210. https://doi.org/10.1186/ar4404.

24. Giles JT, Allison M, Bingham CO, 3rd, et al. Adiponectin is a mediator of the inverse association of adiposity with radiographic damage in rheumatoid arthritis. Arthritis Rheum 2009;61:1248-56. https://doi.org/10.1002/art.24789.

25. Rho YH, Solus J, Sokka T, et al. Adipocytokines are associated with radiographic joint damage in rheumatoid arthritis. Arthritis Rheum 2009;60:1906-14. https://doi.org/ 10.1002/art.24626.

26. Schett G. Autoimmunity as a trigger for structural bone damage in rheumatoid arthritis. Mod Rheumatol 2017;27: 193-7. https://doi.org/10.1080/14397595.2016.1265907.

27. Aletaha D, Alasti F, Smolen JS. Rheumatoid factor determines structural progression of rheumatoid arthritis dependent and independent of disease activity. Ann Rheum Dis 2013;72:875-80. https://doi.org/10.1136/annrheumdis-2012-201517.

28. Solomon DH, Finkelstein JS, Shadick N, et al. The relationship between focal erosions and generalized osteoporosis in postmenopausal women with rheumatoid arthritis. Arthritis Rheum 2009;60:1624-31. https://doi.org/10.1002/ art.24551.

29. Zhang J, Redden DT, McGwin G, Jr., et al. Generalized bone loss as a predictor of three-year radiographic damage in African American patients with recent-onset rheumatoid arthritis. Arthritis Rheum 2010;62:2219-26. https://doi.org/ 10.1002/art.27510.

30. Iwata $T$, Ito $H$, Furu M, et al. Periarticular osteoporosis of the forearm correlated with joint destruction and functional impairment in patients with rheumatoid arthritis. Osteoporos Int 2016;27:691-701. https://doi.org/10.1007/ s00198-015-3256-1. 
31. Mochizuki T, Yano K, lkari K, et al. Correlation between hand bone mineral density and joint destruction in established rheumatoid arthritis. J Orthop 2017;14:461-5. https://doi. org/10.1016/j.jor.2017.07.010.

32. Roux C. Osteoporosis in inflammatory joint diseases. Osteoporos Int 2011;22:421-33. https://doi.org/10.1007/s00198010-1319-x.

33. Kocijan R, Finzel S, Englbrecht $M$, et al. Decreased quantity and quality of the periarticular and nonperiarticular bone in patients with rheumatoid arthritis: a cross-sectional HRpQCT study. J Bone Miner Res 2014;29:1005-14. https:// doi.org/10.1002/jbmr.2109.

34. Book C, Karlsson M, Akesson K, et al. Disease activity and disability but probably not glucocorticoid treatment predicts loss in bone mineral density in women with early rheumatoid arthritis. Scand J Rheumatol 2008;37:248-54. https://doi.org/10.1080/03009740801998747.

35. Compston J. Glucocorticoid-induced osteoporosis: an update. Endocrine 2018;61:7-16. https://doi.org/10.1007/ s12020-018-1588-2.

36. Haugeberg G, Helgetveit KB, Førre $\emptyset$, et al. Generalized bone loss in early rheumatoid arthritis patients followed for ten years in the biologic treatment era. BMC Musculoskelet Disord 2014;15:289. https://doi.org/10.1186/14712474-15-289.

37. George MD, Baker JF. The obesity epidemic and consequences for rheumatoid arthritis care. Curr Rheumatol Rep 2016;18:6. https://doi.org/10.1007/s11926-015-0550-z.

38. Heinze G, Wallisch C, Dunkler D. Variable selection - A review and recommendations for the practicing statistician. Biom J 2018;60:431-49. https://doi.org/10.1002/bimj.2017 00067. 
